\title{
COLOSTOMIA: RELATO DE EXPERIÊNCIA VIVENCIADA POR CLIENTES COLOSTOMIZADOS APÓS HOSPITALIZAÇÃO
}

\author{
Cecília Maria Rodrigues*
}

\begin{abstract}
RESUMO - A pesquisa do tipo descritiva, consiste de entrevistas a um grupo de colostomizados da Associação Mineira dos Ostomizados (AMOS), que fica em Belo Horizonte, Minas Gerais. $O$ instrumento usado foi um formulário que permitiu identificar as necessidades humanas básicas relatadas por indivíduos colostomizados após hospitalização, os elementos da equipe de Enfermagem que prestaram assistência aos pacientes, o atendimento de suas necessidades no perlodo de hospitalização e o tipo de informação recebida por esses individuos durante a hospitalização e/ou após a alta.
\end{abstract}

ABSTRACT - The research, descriptive, consist in interviewing a group of ostomies patients from AMOS (Associação Mineira de Ostomizados), located in Belo Horizonte, Minas Gerais. Buy using a formulary which granted to identify the humans necessities related by them after hospitalization, which members of nursing skiff do the altendance, the instructions maked the patient know during and after the hospitalization.

\section{INTRODUÇÃO}

Sempre que um indivíduo se submete a uma cirurgia, as suas necessidades humanas básicas são afetadas. São consideradas, nesse caso, todas as manifestações apresentadas quando seus sistemas corporais se desequilibram.

Assim, ele apresentará desequilíbrio em três níveis, segundo MOHANA ${ }^{8}$ : psicológico, psicossocial e psicoespiritual. Essas necessidades permanecem latentes e só se manifestam quando se instala o desequilíbrio.

Ainda segundo o mesmo autor, as necessidades psicobiologicas compreendem hidratação, eliminação, oxigenação, higienização etc.; as psicossociais, segurança, amor, comunicação, auto-estima, auto-imagem, atenção, entre outras; as psicoespirituais; religiosa ou teológica, ética ou de filosofia de vida. "As duas primeiras (psicobiológicas e psicossociais) são comuns a todos os seres vivos, enquanto que a última é característica única do homem".

Para exemplificar a manif estação de uma necessidade humana básica, HORTA ${ }^{5}$ cita o amor que se apresentaria sob as formas de insegurança, depressão, angústia, agressividade, anorexia, desvios de comportamento etc.

$\mathrm{Na}$ pessoa hospitalizada, essas necessidades encontram-se exacerbadas, justamente por ela se encontrar nessa condição. E há cirurgias em que algumas dessas necessidades poderão se manifestar mais fortemente que outras, como é o caso da colostomia BRUNNER \& SUDDARTH ${ }^{3}$ a definem como sendo "uma abertura temporária ou permanente do cólon através da parede abdominal", sendo o estoma a parte do cólon exteriorizada na parede abdominal, numa colostomia.

Nesse caso, a necessidade psicobiológica de eliminação estará afetada, pois o trânsito intestinal foi desviado para uma saída abdominal; as necessidades psicossociais de auto-imagem e auto-estima estarão muito mais af etadas, pois as exonerações saem agora pelo abdômen, numa bolsa; o paciente, então, se consi- dera uma pessoa completamente diferente das demais.

Como acadêmica de Enfermagem, percebo que as pessoas submetidas a esse tipo de intervenção cirúrgica apresentam manifestações de certas necessidades humanas básicas mais acentuadas antes e após a cirurgia, principalmente as psicossociais. Estas precisam de um preparo bem feito, que vá diminuir a possibilidade de complicações trans e pós-operatórias. Os cuidados pré-operatórios compreendem preparo psicológico, espiritual e físico. Isto quer dizer: a Enfermagem deve dar-lhes toda atenção quando chegarem ao hospital; deve tentar reduzir medos e tensões o quanto for possível, promover conforto espiritual quando perceber sua necessidade, observar medicação, dieta, fazer controle de líquidos, proceder a técnicas normais de preparo da área operatória, verificar seu estado geral e adotar uma série de condutas de Enfermagem, visando à sua recuperação, sempre procurando atender às necessidades manifestadas e não apenas à conduta médica.

$\mathrm{Na}$ tentativa de identitīcar as percepções que os colostomizados têm após sua saída do hospital quanto ao atendimento de suas necessidades humanas básicas, suas queixas, dificuldades enf rentadas, assistência recebida, principalmente da equipe de Enfermagem, e perspectivas de vida, é que elaborei o presente trabalho.

O desejo de maior aprofundamento no assunto e proposta de soluções referentes ao problema motivaram-me a desenvolver esta pesquisa, como também conhecer a assistência de Enfermagem que os colostomizados recebem no que se refere, principalmente, aos aspectos emocionais, quando de sua internação.

Versando sobre as manifestações das necessidades humanas básicas apresentadas pelos colostomizados após sua hospitalização, esta pesquisa, acredito eu, virá contribuir de algum modo para a discussão e/ou reflexão sobre a prática de Enfermagem junto a discip inas do Curso de Graduação.

Tendo em vista o problema apresentado, foram traçados os seguintes objetivos:

1. Identificar as necessidades humanas básicas

* Acadêmico do Curso de Enfermagem e Obstetrícia da UFMG, bolsista do CNPq-Belo Horizonte - 1988. 
relatadas por indivíduos colostomizados, após hospitalização;

2. Identificar junto a indivíduos colostomizados qual (quais) elemento(s) da equipe de Enfermagem prestaram-lhe assistência e se lhes forneceram informações a respeito do problema;

3. Verificar junto aos indivíduos colostomizados se as suas necessidades apresentadas no período de hospitalização foram atendidas pela equipe de Enfermagem;

4. Verificar o tipo de informação recebida pelo indivíduo colostomizado durante a hospitalização e/ou após a alta hospitalar.

\section{METODOLOGIA}

Para alcançarmos os objetivos propostos, foì realizada uma pesquisa descritiva compreendendo o período de outubro de 1987 a outubro de 1988.

A localização dos indivíduos colostomizados, pôde ser feita através de contatos informais com a Diretoria da Associação Mineira dos Ostomizados AMOS.

A AMOS é uma entidade recém-criada, ainda sem sede, funcionando numa sala cedida pela Diretoria do Posto de Atendimento Médico do INSTITUTO NACIONAL DE PREVIDÊNCIA SOCIAL onde se encontra desde fevereiro de 1988. Sua Diretoria é composta de um Presidente, um Secretário, 1ㅇ e 2o Tesoureiros e um Relações Públicas. É filiada à Sociedade Brasileira dos Ostomizados. O objetivo da Associação é dar assistência integral aos colostomizados: apoio sócio-econômico, cultural, físico, etc.

Qualquer pessoa que tenha conhecimento da Associação são dar assistência integral aos colostomizados: apoio sócio-econômico, cultural, físico etc. lostomizados, etc. A rotina é a seguinte:

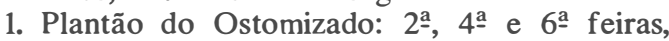
sempre com a enfermeira;

2. Serviço de Enfermagem;

3. Serviço Social; AMOS.

4. Participação nas reuniões de atividades da

As reuniōes se realizam no último sábado do mês, às $19 \mathrm{~h}$, e na segunda $3^{\mathrm{a}}$ feira do mês, às $13 \mathrm{~h} 30 \mathrm{~m}$; geralmente há troca de experiências, expressão de sentimentos, de dificuldades na convivência com a ostomia, facilidades (irrigação, alimentação).

São atividades da AMOS:

- plantão;

- visitas pré e pós-operatórias; sas);

- contribuição em dinheiro (mas não para as bol-

- bazar;

- distribuição de bolsas;

- notícias sobre trabalhos que estão sendo feitos;

- orientação e esclarecimento quanto a cirurgiascolostomia, ileostomia e urostomia - (com a participação de médicos).

A Associação conta também com uma enfermeira e duas assistentes sociais, que fazem um trabalho de assessoria técnica, suporte e apoio.

A atual situação da AMOS:

- plane ja suas outras atividades;
- recebe contribuições;

- atende pessoas (com vínculo previdenciário ou não);

- funciona precariamente (numa sala cedida, no Posto de Assistência Médica). Reconhecida como de utilidade pública em nível estadual e está pesquisando seus direitos;

- conta com aproximadamente 100 associados, sendo 75 colostomizados, com boa freqüência às reuniōes.

\section{Critérios para Seleção da Amostra}

Contactamos com a Direção da AMOS e solicitamos autorização para realizar o estudo junto aos associados. Após a permissão, participamos de uma reunião ordinária que contou com a presença dos associados, para um primeiro contato; apresentamos os objetivos do trabalho e solicitamos verbal e individualmente a permissão de cada um para participar da pesquisa.

Havia aproximadamente 30 pessoas presentes, das quais 16 aceitaram participar da pesquisa.

Agendamos dia e hora com cada indivíduo e anotamos seu endereço. Dois colostomizados não residiam em Belo Horizonte e nos propusemos a ir também em suas residências - em Ouro Preto e em Esmeraldas, respectivamente.

Foram eliminados do total de colostomizados que aceitaram participar da pesquisa quatro indivíduos: utilizamos suas entrevistas para testagem do instrumento de coleta de dados. Dois foram eliminados porque foi impossível localizar seus endereços.

\section{Fomulário para Coleta de Dados}

A fim de que o trabalho prosseguisse na etapa da Coleta de Dados, foi elaborado um formulário (Anexo I) composto de duas partes: a primeira compreende as questões 01 a 08 e refere-se à identificação do cliente, como sexo, idade, escolaridade, religião, profissão, vínculo e situação perante a Previdência. A segunda parte aborda mais especificamente as informaçōes a respeito da situação em que ele se encontrava; identificação de necessidades, assistência recebida pela equipe de Enfermagem, atendimento de suas necessidades, orientação recebida e participação da AMOS.

\section{Coleta de Dados}

Após a permissão dos colostomizados, partimos para entrevistá-los em seus domicílios, contando com a sorte para encontrá-los, uma vez que não tinham telefone.

Conseguimos um total de 10 indivíduos para compor a amostragem.

Os dados foram coletados e tabulados manualmente e serão apresentados de forma descritiva, em tabela e em quadro, quantitativamente e em números absolutos.

\section{RESULTADOS E DISCUSSÃO}

Os resultados são apresentados segundo sua ordem no instrumento de coleta de dados: 


\section{Características da População Estudada}

Como características da população estudada, foram encontradas as seguintes:

1. Constitui-se de 10 clientes colostomizados, distribuídos, segundo o sexo, da seguinte maneira: 2 do sexo masculino e 8 do sexo feminino; 8 eram casados, 1 solteiro e 1 viúvo. A distribuição de colostomizados por sexo e estado civil pode ser vista na Tabela 1 .

\section{Tabela 1 \\ CARACTERÍSTICAS DE INDIVÍDUOS COLOSTOMIZADOS, POR SEXO E ESTADO CIVIL - BELO HORIZONTE - 1988}

\begin{tabular}{l|c|c|c}
\hline \multirow{2}{*}{\begin{tabular}{l|c|} 
ESTADO \\
CIVIL
\end{tabular}} & \multicolumn{2}{|c|}{ S E X O } & \multirow{2}{*}{ TOTAL } \\
\cline { 2 - 3 } & Masculino & Feminino & \\
\hline SOL TEIRO & - & 1 & 1 \\
CASADO & 2 & 6 & 8 \\
VIÚVO & - & 1 & 1 \\
OUTROS & - & - & - \\
\hline TOTAL & 2 & 8 & 10 \\
\hline
\end{tabular}

2. Quanto à idade, os indivíduos apresentavam $33,41,46,48,49,52,55,57,58$ e 59 anos.

3. Quanto à escolaridade, foram encontrados os seguintes dados: 1 indivíduo analfabeto, 8 com o $1^{\text {o }}$ grau incompleto e apenas 1 com o $3^{\circ}$ grau completo.

4. Quanto à religião, encontraram-se 9 católicos e 1 protestante.

5. Segundo a profissão, detectou-se a seguinte distribuição: 6 colostomizados são do lar, 1 é ascensorista, 1 tecelã, 1 trabalhador braçal e 1 advogado.

6. Em relação à classificação e situação previdenciária, encontraram-se 9 colostomizados vinculados ao INPS e 1 ao FUNRURAL, sendo 6 dependentes, 3 aposentados e 1 segurado.

7. Hospital onde esteve internado

Os 10 indivíduos foram internados em hospitais da rede privada, sendo $8 \mathrm{em}$ um hospital filantrópico de Belo Horizonte e 2 em hospitais do Município de Contagem e do Estado de São Paulo.

\section{Tempo de Colostomia}

Foram verificados $4 \mathrm{c}$ ientes com colostomia durante um período que variou de 5 a 7 meses; quanto aos 6 restantes, esse período variou de 2 a 18 anos.

9. Motivo da Colostomia

Os motivos que justificaram a indicação de colostomia foram tumor retal (responsável por 8 cirurgias), processo inflamatório (por 1) e estreitamento do canal retal (por 1).

10. Informações a Respeito da Situação em que se Encontrava (grau de conhecimento da cirurgia e participação da família)

Dos 10 clientes entrevistados, constatou-se que 8 não sabiam a que tipo de cirurgia seriam submetidos, apenas 2 receberam tal informação. Para 8 , houve apoio da família, só agora a família de 1 está aceitando a situação e, quanto ao último, o marido é o único que não apóia.

\section{Identificação de Necessidades Humanas Básicas}

Após o levantamento dos problemas, foram identificadas as necessidades apresentadas no quadro abaixo, segundo o modelo de HORTA ${ }^{6}$.

\section{Experiências Vivenciadas na Hospitalização}

\section{Assistência recebida da equipe de Enfermagem}

Os elementos que prestaram assistência ao paciente: neste item os valores obtidos se contrabalançam, pois 5 indivíduos disseram ter sido atendidos pela equipe de Enfermagem e 5 indivíduos relataram terem sido atendidos por enfermeiras.

\section{zação}

2. Se conheceu o Enfermeiro durante a Hospitali-

Dos 10 clientes entrevistados, 6 conheceram o enfermeiro, 3 não lembram e 1 não faz distinção entre o enfermeiro e os demais membros da equipe.

3. Se recebeu informação antes elou após a Cirurgia e de que membro da equipe

Oito não receberam qualquer tipo de informação e 2 receberam alguma, da enfermeira, após a cirurgia.

4. Quanto ao atendimento de suas Necessidades

As 10 pessoas relatam que as psicobiológicas fo ram atendidas por médicos e pela equipe de Enfermagem; os 10 porém, não foram atendidos em suas necessidades psicossociais de informação e segurança emocional, e apenas 1 não teve sua necessidade psicoespiritual atendida (Quadro 1).

\section{No que se refere à orientação recebida}

Sete dos indivíduos entrevistados receberam orientação somente do médico; 2 não receberam nenhum tipo de orientação da equipe de Saúde, dando-se sua aprendizagem inteiramente na AMOS; 1 as recebeu dos estudantes de Medioina e nenhum deles se lembra de ter conhecido nutricionista, psicólogo, ou outro membro da equipe de Saúde.

\section{Sobre a AMOS}

Os 10 clientes entrevistados relatam ter tomado conhecimento da Associação pelo médico(a) que os atendeu no hospital ou no controle do PAM Sagrada Família; 1 recebeu uma carta da Associação e resolveu conhecê-la; 1 foi convidado por uma das assistentes sociais a fazer parte da Associação.

Quanto à expectativa dos indivíduos entrevistados com relação à AMOS, verificou-se que 8 esperam que a mesma "continue dando apoio, compreensão, ajuda em bolsa etc.", sendo isso que recebem; 1 ainda não conhece nada sobre a AMOS, ficando difícil uma avaliação, e 1 acha que a mesma ainda não of erece muito, mas que vão procurar melhorá-la.

Em relação ao tempo em que freqüentam a AMOS, esse variou de 1 mês a aproximadamente 1 ano e meio. 


\section{Quadro 1 \\ NECESSIDADES HUMANAS BÁSICAS RELATADAS PELOS INDIVÍDUOS \\ COLOSTOMIZADOS ANTES E APÓS A CIRURGIA - 1988.}

\begin{tabular}{|c|c|c|c|c|c|c|c|c|}
\hline \multicolumn{3}{|c|}{$\begin{array}{l}\text { NECESSIDADE } \\
\text { PSICOBIOLÓGICA }\end{array}$} & \multicolumn{3}{|c|}{$\begin{array}{l}\text { NECESSIDADE } \\
\text { PSICOSSOCIAL }\end{array}$} & \multicolumn{3}{|c|}{$\begin{array}{c}\text { NECESSIDADE } \\
\text { PSICOESPIRITUAL }\end{array}$} \\
\hline Tipo & Antes & Depois & Tipo & Antes & Depois & Tipo & Antes & Depois \\
\hline $\begin{array}{l}\text { 1. Eliminação } \\
\text { intestinal }\end{array}$ & 10 & 4 & $\begin{array}{l}\text { 1. Segurança } \\
\text { emocional }\end{array}$ & 6 & 10 & $\begin{array}{l}\text { 1. Segurança } \\
\text { espiritual }\end{array}$ & 1 & 1 \\
\hline $\begin{array}{l}\text { 2. Percepção } \\
\text { dolorosa }\end{array}$ & 6 & 2 & $\begin{array}{l}\text { 2. Informação } \\
\text { e/ou comunic. }\end{array}$ & 6 & 10 & & & \\
\hline $\begin{array}{l}\text { 3. Integridade } \\
\text { cutâneo- mucosa }\end{array}$ & 5 & 2 & 3. Gregária & 2 & 1 & & & \\
\hline 4. Nutrição & 4 & 9 & $\begin{array}{l}\text { 4. Educação para } \\
\text { saúde }\end{array}$ & 1 & - & & & \\
\hline 5. Circulação & 3 & 2 & 5. Sexualiade & 1 & 2 & & & \\
\hline $\begin{array}{l}\text { 6. Integridade } \\
\text { física }\end{array}$ & 3 & - & $\begin{array}{l}\text { 6. Lazer e/ou } \\
\text { recreação }\end{array}$ & 1 & 6 & & & \\
\hline $\begin{array}{l}\text { 7. Regulação } \\
\text { imunológica }\end{array}$ & 2 & 1 & 7. Atenção & - & 5 & & & \\
\hline 8. Sono e repouso & 1 & 6 & 8. Auto-imagem & - & 9 & & & \\
\hline 9. Hidratação & 1 & - & 9. Auto-estima & - & 5 & & & \\
\hline $\begin{array}{l}\text { 10. Exercícios e } \\
\text { atividades físicas }\end{array}$ & 1 & 2 & 10. Liberdade & - & 4 & & & \\
\hline $\begin{array}{l}\text { 11. Eliminação } \\
\text { vesical }\end{array}$ & 1 & - & $\begin{array}{l}\text { 11. Auto-reali- } \\
\text { zação }\end{array}$ & - & 2 & & & \\
\hline 12. Motilidade & - & 2 & 12. Aceitação & - & 6 & & & \\
\hline & & & 13. Participação & - & 3 & & & \\
\hline
\end{tabular}

\section{Quanto ao seu Futuro}

Cinco colostomizados esperam que sua colostomia continue funcionando bem, como está; 2 esperam se acostumar definitivamente com ela e voltar à sua vida normal; 2 esperam fechá-la posteriormente; e 1 , que haja algum dia uma cirurgia para reimplantação do reto.

Com base nos resultados apresentados, discutese:

Numa cirurgia (programada ou não), a ansiedade pré-operatória é uma situação já esperada. É fruto de uma insegurança vivida pelo indivíduo, que não pode prever o que o aguarda no futuro. Sem saber como sua auto-imagem estará af etada, seu ego, então, lança mão de recursos conhecidos como mecanismos de defesa, que são formas encontradas para diminuir as tensões do sub-consciente, mantendo-o em equilíbrio, e a ansiedade é um desses mecanismos.
No estudo em questão, numa colostomia, programada ou não, a situação não é diferente. Os níveis de ansiedade irão variar de indivíduo para indivíduo e influenciar de alguma forma no processo de aprendizagem pelo qual passa o indivíduo nessa nova situação.

Outro ponto que deve ser analisado é a influência exercida pelo grau de escolaridade nessa aprendizagem. O não acesso aos estudos, fruto de um governo falho e de uma sociedade marginalizadora, acarreta, pois, desinformação e, conseqüentemente, desconhecimento do que seria básico à educação do indivíduo. Nessa população predominam o primeiro grau incompleto e o analfabetismo, portanto, a aprendizagem dos novos hábitos e as mudanças ocorridas no organismo se processam de forma lenta, gerando, às vezes, ansiedade, conf orme relatam os indivíduos.

A idade dos indivíduos estudados varia de 33 a 59 anos e, na sua maioria são católicos. A condição de 
católicos não implica em que sejam realmente praticantes, mas que sentem a presença de um Deus em cujas mãos repousam todos os direitos sobre sua vida.

Nesse estudo, felizmente apenas um cliente não teve sua necessidade psicoespiritual atendida, o que não significa estar sendo boa a assistência, uma vez que uma necessidade, seja de que nível for, se manifesta, ela deve ser prontamente atendida, ou, pelo menos, deve haver tentativa de fazê-lo.

À luz dos dados coletados e analisando-se a situação em que se encontra hoje a Enfermagem, nota-se, por parte dos dirigentes dos hospitais privados, um não compromisso com o paciente, uma vez que não contratam enfermeiros para melhorar a qualidade da assistência de Enfermagem. E nos hospitais da rede filantrópica, aliada a uma série de limitações impostas pela administração hospitalar e pelo governo, está o descompromisso de uma grande parte dos enfermeiros, que deixa de lado a assistência - que deveria ter prioridade - para acumular funções ou desempenhar outras que não lhe se jam afins.

Considerando todas as particularidades que envolvem a assistência de Enfermagem está um ponto fundamental: o preparo do paciente, seja a cirurgia temporária ou permanente.

Assim como BRUNNER \& SUDDARTH $^{3}$, MARTEL L I ${ }^{7}$ também propõem: "Preparar o paciente..." e identificar suas necessidades de aprendizagem. Quando a ação sistêmica da Enfermagem se volta para a orientação prévia, o paciente acata melhor a terapêutica proposta e a assistência da equipe de Saúde, mostrando-se mais seguro, colaborando melhor e menos susceptível a alterações físicas e comportamentais.

Nesse estudo oito dos clientes desconheciam totalmente a colostomia conforme alguns depoimentos: “... acho que eles achavam que eu tinha cabeça boa, não precisava preparar. Mas eu acho que eles deviam explicar bem essas coisa, né?" e "eu sabia que tinha uma cirurgia onde a pessoa ficava com um furo na parte abdominal, mas não sabia como era...", embora desconhecendo a cirurgia manifestaram dese jo de receber informação acerca do tratamento, o que segundo eles não foi feito.

É tão importante quanto o preparo para a cirurgia, como afirmam BELLAND \& PASSOS $^{2}$ é o papel que a família desempenha na vida destas pessoas. Oito das dez pessoas entrevistadas sentiram o apoio da família e percebe-se, pelos relatos, como essa ajuda foi importante.

Ao analisarmos as necessidades humanas básicas relatadas pela população desse estudo, há coerência com a bibliografia consultada. Assim como ZERBERTTO $^{10}$ e após análise do quadro 1, nota-se o seguinte:

A eliminação intestinal e a percepção dolorosa, que eram os problemas básicos antes da cirurgia, baixaram seus índices consideravelmente após a cirurgia.

Quanto à nutrição, após a cirurgia o problema acometeu a quase todos os indivíduos, devendo-se o fato à intolerância a certos alimentos que mesmo não sendo contra-indicados, variando de indivíduo para indivíduo pode provocar constipação, diarréia, odores fétidos., "... e era o que eu mais gostava: feijão preto...", “... dão gases, mau cheiro nas fezes, atrapalham o intestino, desandam, soltam ele, né?".

O sono e o repouso e a motilidade, que pratica- mente não se manifestaram antes da cirurgia, elevaram seus índices no pós-operatório, sendo que o sono foi uma necessidade manifestada por mais da metade dos clientes.

O fato se deve a vários motivos: preocupação de como cuidar e higienizar a bolsa e o estoma, controle das exonerações, desconforto causado pela bolsa, limitação das atividades rotineiras etc.

No que diz respeito às necessidades psicossociais, no presente estudo, percebe-se um aumento dos índices das necessidades de segurança, apoio emocional e informação e/ou comunicação para a totalidade dos clientes, após a cirurgia.

Todo paciente que não tem suas necessidades psicossociais atendidas no pós-operatório tem sua reabilitação de algum modo prejudicada. Informações não podem ser dadas no momento da alta hospitalar. Conforme ZERBETTO, é preciso que o processo de reabilitação baseado em princípios científicos que atendem às reais necessidades do indivíduo seja posto em prática logo após a cirurgia e não quando o paciente está em alta hospitalar.

A sexualidade, outra necessidade psicossocial identificada é um processo que pode atingir algumas pessoas, uma vez que eles certamente verão esta cirurgia como mutiladora e como ameaça à sua atividade sexual.

No estudo em tela, vê-se claramente a situação: "como a esposa não é mais a mesma coisa, isso não; mas está bom".

As necessidades de lazer e/ou recreação e liberdade e participação manifestaram-se após a cirurgia em mais da metade dos entrevistados.

“... É ter que levar a bolsa prá todo lugar que eu vou, porque, se eu esquecer a bendita em casa, é um desastre".

Além disso, como comenta SANT'ANA ${ }^{9}$, diante de uma sociedade que valoriza extremamente a boa aparência e o controle de odores, o paciente sente-se receoso quanto à possibilidade de eliminação de odores desagradáveis, bem como teme que percebam que ele está fazendo uso de uma bolsa coletora ou de um equipamento similar:

“... eu fiquei muito nervosa, chorava muito, achava que era só eu que tinha aquele problema; que ninguém mais tinha";

"... cismei que não sinto cheiro de limpeza no corpo";

“... aqui b́ na minha barriga, nossa mãe!"

Quanto à aceitação, esta dependerá de quanto tempo o colostomizado levará para incorporar a nova imagem à sua estrutura psíquica, uma vez que a imagem de seu corpo foi mutilada:

"Mas agora eu vou ficar com isso?";

"Ninguém acha bom ter que ficar trocando uma bolsa toda hora. Vocês, que s̃̃o normais, sentam no vaso e pronto; eu não, já não é mais como antes";

“... tem gente que não gosta de falar essas coisas, eu não importo não...";

, “... foi um desastre. Prá mim foi o fim. Eu me senti uma aleijada e, quando fiquei sabendo que as fezes iam sair por aquele buraco, fiquei desesperada e abri a boca a chorar".

Todo indivíduo sente necessidade de atenção para com sua pessoa, aliada ao desejo de cuidado e preservação do corpo. 
Atenção e auto-estima estão muito interligados, pois, uma vez que o colostomizado se sente bem cuidado e observado, isso se torna um incentivo para que ele também lute pela preservação do seu corpo e conseqüentemente caminhe para uma aceitação mais rápida.

Da necessidade psicoespiritual, sabe-se que praticar sua religião é, para o indivíduo, além de uma necessidade, um direito. De um modo geral, ao se verem doentes, as pessoas se voltam para a religião em busca de apoio e conforto, como referem BELLAND \& PASSOS ${ }^{1}$.

Esse conforto poderá ser dado pelos elementos da equipe de saúde, ou por líderes religiosos da comunidade do paciente, como um deles relata: “... um padre muito amigo nosso, sabe?"

A fim de procurar minimizar os problemas le vantados é preciso então que o enfermeiro dentro de suas limitações:

a) identifique as necessidades humanas básicas de seus clientes :

b) procure compreender as atitudes de seus clientes;

c) dê informações em tempo hábil a seus clientes;

d) ouça o paciente;

e) faça um plano de cuidados; e

f) faça um exame minucioso das condições do estoma.

E todas essas medidas deverão ser tomadas, principalmente a última, com novo enfoque no pós-operatório que é onde as necessidades de informação e/ou comunicação, apoio emocional etc., estarão muito mais exercebadas.

Do apoio emocional, pode-se dizer: "A arte de ouvir é tão importante quanto a de falar. O profissional deve ter a capacidade para detectar o que não é dito explicitamente", nos dizeres de CARVALHO ${ }^{4}$.

Contudo, com base nas análises feitas anteriormente, a discussão se dirige para um ponto muito importante: o não conhecimento da enfermeira pelo paciente e/ou vice-versa, como se nota a seguir através de relato dos pesquisados:

"Ela passou no meu quarto, mas eu acho que ela nem sabia o que eu tinha operado".

Conforme o relato que se segue, entre outros, nota-se que os entrevistados sentiram muito a falta de apoio emocional e de informação antes e após a airurgia e, como conseqüência, todo o aprendizado teve de se dar na Associação:

"As enfermeiras são muito atenciosas, mas são muito afastadas dos pacientes. Só respondem o que a gente pergunta".

Após tudo que já foi visto em termos de importância da assistência que deve ser dada ao indivíduo questiona-se: por que os planos social e espiritual não têm a mesma importância das necessidades psicobiológicas? Não é preciso dizer que planejar cuidados de Enfermagem é uma tarefa que exige colaboração de toda equipe de saúde.

Como parte da assistência prestada na tentativa de somar suas necessidades psicossociais de informação e/ou comunicação, apoio emocional e cultural está o conhecimento da existência de clubes e associações de colostomizados, a fim de a eles encaminhá-los posteriormente.

Segundo relatos, parece-nos que os enfermeiros que atenderam aos colostomizados do estudo não sabiam da existência de clubes e/ou associações, pois todos os clientes foram encaminhados por médicos, ou receberam uma carta-convite para que ingressassem na mesma.

"O médico me disse da Associação. Que tinha uma reunião muito boa na Sagrada Família. Aí eu fui”.

Analisando os resultados, pode ser observado que os clientes estão satisfeitos com a AMOS, no que diz respeito a apoio emocional, aprendizado, auxílio com bolsas etc., sendo que a Associação atende a todas as suas expectativas:

“... e dando apoio e força prá gente";

“... lá eu vejo que tem outras pessoas com o mes mo problema que eu";

“... Eu tinha falta de coragem, mas recebi tantas cartas e telegramas que acabei indo. Foi a maior festa quando apareci lá; todos me receberam de braços abertos, fui apresentada para todos, foi muito bom".

\section{CONCLUSÕES}

Tentou-se apresentar, nas páginas anteriores, uma análise do relato da experiência vivida por indivíduos colostomizados após sua saída do hospital e que agora fazem parte da Associação Mineira dos Ostomizados.

Para execução do trabalho, partiu-se do princípio de que para que haja uma reabilitação satisfatória do paciente, este deve receber assistência nos três níveis de suas necessidades humanas básicas. Caso isso não ocorra, sua recuperação estará prejudicada.

Acreditamos que nossas conclusões não se jam um "finalmente" para o estudo, mas uma porta aberta para o início de vários outros trabalhos que, de algum modo, contribuirão para os corpos docente e discente de Enfermagem, bem como para a prática de Enferma. gem.

Finalmente, após exaustivas análises das entrevistas e dentro das limitações deste estudo pudemos chegar às seguintes conclusões:

1 - Em relação ao. primeiro objetivo, pudemos identificar como necessidades humanas básicas relatadas por indivíduos colostomizados:

a) psicobiológicas: nutrição, sono e repouso, eliminação intestinal, percepção dolorosa, integridade cutâneo-mucosa, circulação, exercícios e atividades físicas e motilidade;

b) psicossociais: segurança emocional, informação e/ou comunicação, auto-imagem, lazer e/ou recreação, aceitação, atenção, auto-estima, liberdade, participação, sexualidade e auto-realização.

2 - Quanto ao segundo objetivo, pudemos concluir que a maioria dos colostomizados foi atendida pelo auxiliar de enfermagem e que esse não lhes forneceu informações a respeito da cirurgia. Praticamente, nenhum paciente conheceu, foi atendido ou orientado pelo enf ermeiro.

3 - Pelos relatos apresentados, concluímos que as necessidades manifestadas no período de hospitalização foram atendidas parcialmente.

$4-\mathrm{E}$, quanto à orientação durante a hospitalização, a maioria só recebeu informações sobre como cuidar da colostomia e nutrição no momento da alta hospitalar. Após a alta hospitalar, receberam apoio da 
AMOS, sendo encaminhados por médicos. Nessa Associação, obtiveram todo tipo de informação e assistência necessários à sua reabilitação.

\section{REFERÊNCIAS BIBLIOGRÁFICAS}

1 BELLAND, Irene, L. \& PASSOS, Joyce Y. Enfermagem clínica. Aspectos fisiopatológicos e psicossociais. 3 ed., São Palo, E.P.U., 1978. Vol. 1, 446 p. Apud: FERRAZ, A.F. et alii. Assistência a pacientes em fase terminal. Rev. Bras. Enf., Braślia, 39(1): 50-60, jan./mar. 1986.

2

. A Enfermagem na reabilitação. Enfermagem clínica. Aspectos fisiopatológicos e psicossociais. 3 ed., São Paulo, E.P.U., 1979. Vol. 3, cap. 18, p. 155-75.

3 BRUNNER, L.S.; SUDDARTH, D.S.. Enfermagem médico-cirúrgica: distúrbios do sistema digestivo. In: _. Prática de enfermagem. 2 ed., Rio de Janeiro, Guanabara, Koogan, 1980. Vol. 1, parte 1, cap. 8, p. 451-573.

4 CARvalho, Dacle Vilma. Princípios da assistência de enfermagem nas urgências cirúrgicas. In: SILVA, Alci- no Lázaro da. Cirurgia de urgência. 5 ed., Rio de Janeiro, MEDSI, 1985. Vol. 2, seção 17, cap. 10, p. 1682-5.

5 HORTA, Wanda de A. Necessidades humanas básicas: consideraçōes gerais. Enf. Novas Dimens., São Paulo, 1 (5): 266-8, nov./dez., 1975.

6 . Processo de enfermagem. In: Processo de Enfermagem. São Paulo, E.P.U., 1979. Parte 2, p. $35-74$.

7 MARTELLI, Zaíra Benedini. Necessidades de aprendizagem da pessoa colostomizada: impressão diagnóstica do enfermeiro através da observação militante e taxionomia de objetivos educacionais. Ribeirão Preto, USP. 1983. 158 p. (Tese, Mestre em Enfermagem Psiquiátrica).

8 MOHANA, João. $O$ mundo e eu. 2 ed., Rio de Janeiro, AGIR, 1964. Apud: HORTA, Wanda de A. Necessidades humanas básicas: considerações gerais. Enf. Novas Dimens., São Paulo, 1 (5): 266-8, nov./dez., 1975.

9 SANT'ANA, Maria Helena Pereira. A enfermeira e as ostomias. Enf. Novas Dimens. 5(2): 39-46, 1979.

10 ZERBETTO, G. M. Reabilitação do paciente ostomizado. Rev. Paul.Enf., São Paulo, O(0): 16-20, jan./fev., 1981. 